\title{
Vacuum-Assisted Ex situ Lift Out for Plan View FIB Specimen Preparation
}

\author{
Lisa Marie Lowery ${ }^{1}$, Lucille A. Giannuzzi ${ }^{2}$, Ping Lu ${ }^{1}$, Paul G. Kotula ${ }^{1}$ and Joseph R. Michael ${ }^{1}$ \\ 1. Sandia National Laboratories, Materials Characterization, Albuquerque, NM. \\ 2. EXpressLO LLC, Lehigh Acres, FL.
}

Plan view focused ion beam (FIB) specimen preparation for scanning/transmission electron microscopy $\mathrm{S} / \mathrm{TEM}$ is possible but rarely performed due to complex and time-consuming processing manipulation steps. Plan view specimens have been FIB prepared from pre-thinned or "H-bar" samples [1,2], via in situ lift out methods [3,4] or via ex situ lift out methods $[5,6]$. These traditional techniques require either initial sample thinning, or multiple sample and/or grid rotations or manipulations to correctly orient the region of interest. This paper describes a novel and efficient vacuum-assisted ex situ lift out technique for plan view FIB specimen preparation.

A $20 \times 20 \mu \mathrm{m}$ region was defined and protected via electron beam deposited Pt prior to FIB deposited Pt. A pattern in the shape of a "U" was FIB milled in parallel mode at $45^{\circ}$ on each side (i.e., $7^{\circ}$ stage tilt on an FEI Helios 660/G3 UC DualBeam) using a $180^{\circ}$ stage rotation to create an unsupported and freestanding wedge-shaped sample. The bulk sample was moved to an EXpressLO Nicola 800 ex situ lift out station equipped with an Aspirato vacuum module where a $30^{\circ}$ beveled hollow probe was used for the lift out to slotted EXpressLO grids [7]. The lift out process took only minutes to perform.

Figure 1 shows the lift out process and TEM results. A probe attack angle of $30^{\circ}$ (from the horizontal) with vacuum applied was used to lift out the sample wedge (see Figure 1a). The probe was raised up and manually rotated $180^{\circ}$ (Figure $1 \mathrm{~b}$ ) and then lowered through the grid slot with the plan view orientation parallel to the grid surface as shown in the SEM image in Figure 1c, so as to place the plan view plane of interest against the slotted grid. FIB deposited Pt was added to secure the sample to the grid as per the SEM image in Figure 1d. A plan view FIB specimen then was milled following standard thinning procedures. Figure 1e shows a low magnification bright field (BF) TEM image of a (100) plan view Si specimen. Note the bend contour intersections indicating the real zone pattern. A [100] selected area diffraction pattern (SADP) is inset in the image. Figure 2 shows STEM high angle annular dark field (HAADF) plan view images at (a) low magnification and (b) high resolution, of a $\mathrm{ZnO}: \mathrm{LaSrMnO}_{3}$ composite thin film grown epitaxially on $\mathrm{SrTiO}_{3}$ substrate by pulsed laser deposition prepared via the plan view specimen preparation method described above. The TEM work was performed on an FEI TF30 operating at $300 \mathrm{keV}$ and the STEM work was performed on a probe aberration-corrected FEI Titan G2 $80-200$ operating at $200 \mathrm{kV}$.

This vacuum assisted ex situ lift out plan view method is fast and easy and eliminates expensive FIB time required for in situ lift out and complicated sample and/or grid manipulation. The slotted EXpressLO grids provide precise sample placement and stability, and allows for standard FIB processing necessary to create conventional TEM or high resolution STEM quality specimens [8].

References:

[1] R.J. Young et al, MRS Proceedings 199 (1990), p. 205.

[2] R Anderson and S.J. Klepeis in "Introduction to Focused Ion Beams", eds. F.A. Stevie and L.A. (Giannuzzi, Springer, NY) p. 173. 
[3] A.E.M De Veiman, Mater. Sci. Eng. B 102 (2003), p. 63.

[4] T. Kamino et al, in "Introduction to Focused Ion Beams" eds. F.A. Stevie and L.A. (Giannuzzi, Springer, NY) p. 229.

[5] F.A. Stevie et al, AIP Conference Proceedings 449 (1998), p. 868.

[6] R.M. Langford et al, J. Vac. Sci. Technol. 19 (2001), p. 755.

[7] L.A. Giannuzzi et al, Microsc. Microanal. 21 (2015), p. 1034.

[8] Sandia National Laboratories is a multimission laboratory managed and operated by National Technology and Engineering Solutions of Sandia, LLC, a wholly owned subsidiary of Honeywell International, Inc., for the U.S.

Department of Energy's National Nuclear Security Administration under contract DE-NA0003525.

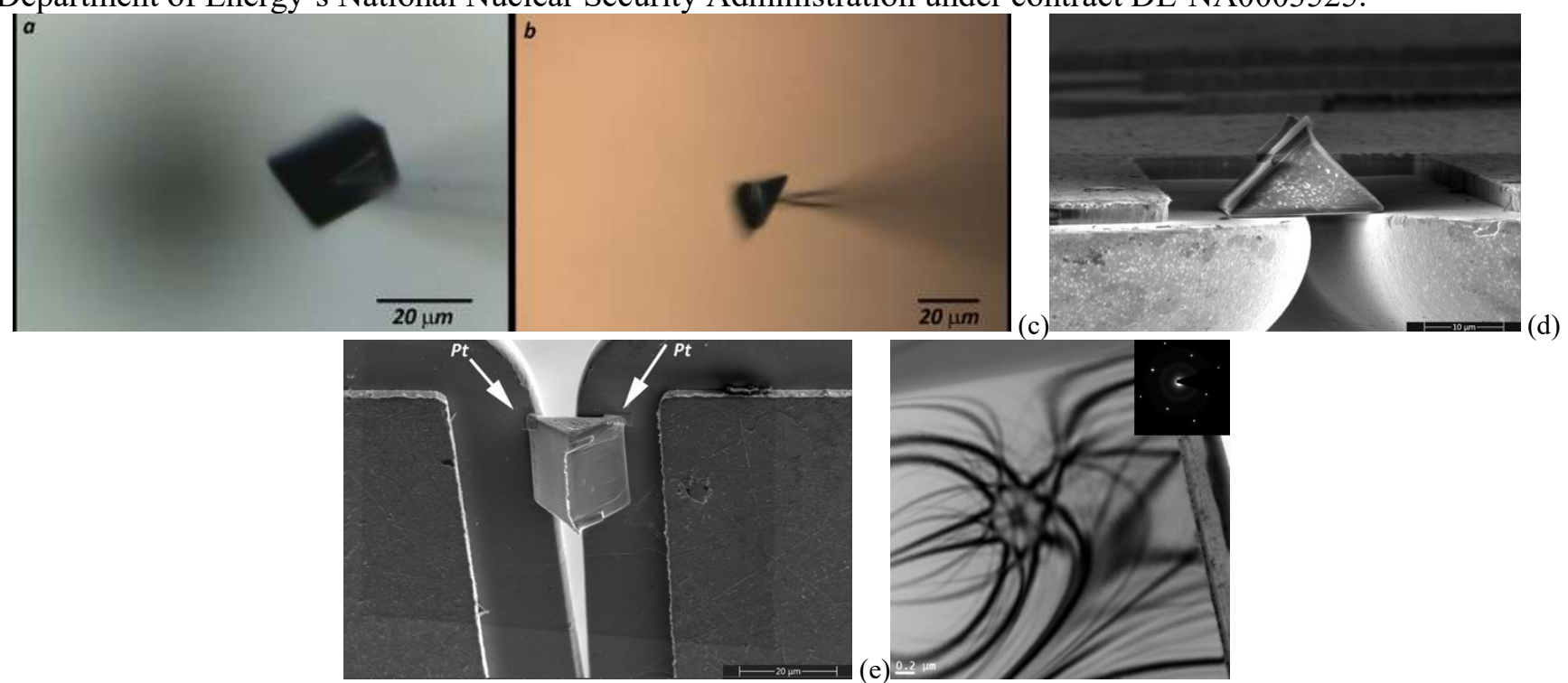

Figure 1. Vacuum-assisted ex situ lift out of a FIB milled (001) plan view Si specimen (a) lifted out from the bulk sample. (b) probe rotated $180^{\circ}$. (c) SEM image of plan view orientation. (d) SEM image of lift out with Pt deposition added. (e) BF TEM image of Si plan view specimen and inset [100] SADP.
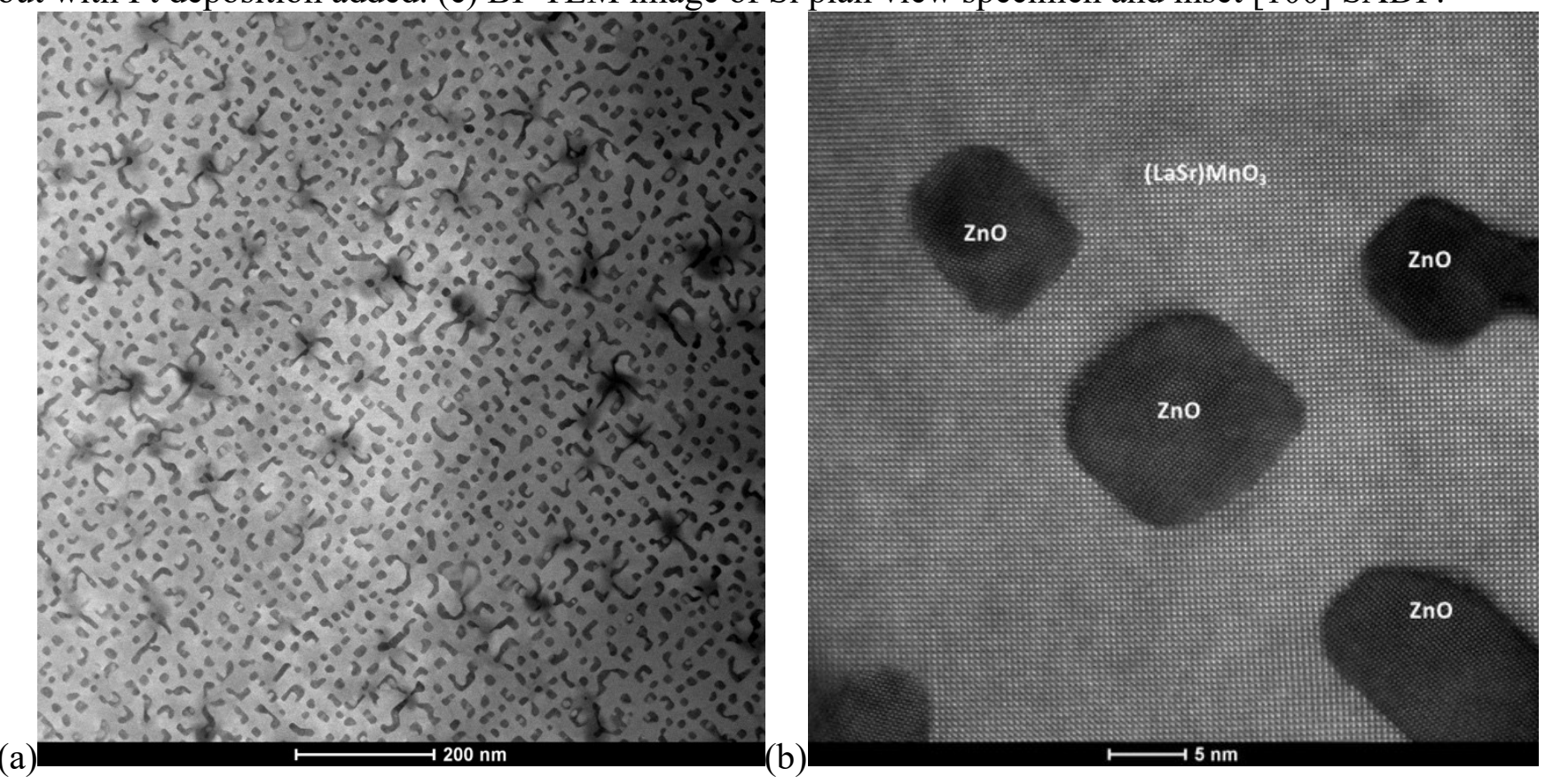

Figure 2. STEM HAADF plan view images of a $\mathrm{ZnO}: \mathrm{LaSrMnO}_{3}$ composite thin film. a) Low magnification overview image. b) High resolution structural image of the composite film. 